\title{
SPACE CLOSURE IN BIALVEOLAR DENTAL PROTRUSION CASES - A COMPARATIVE COMBINATION METHOD
}

\author{
CHAITANYA N ${ }^{1}$, ARSHAD AM ${ }^{1}$, PRAVEEN KRK ${ }^{2 *}$, PRASHANT C ${ }^{2}$, SANDEEP BAILWAD ${ }^{3}$, NAVIN P ${ }^{4}$, BALAJI $^{4}$, \\ YOGESH C ${ }^{5}$, SAURAB K
}

${ }^{1}$ Department of Orthodontics and Dentofacial Orthopedics, Narayana Dental College and Hospital, Nellore, Andhra Pradesh, India. ${ }^{2}$ Department of Orthodontics, Faculty of Dentistry, SEGi University, Kota Damansara, Malaysia. ${ }^{3}$ Department of Pedodontics, MAHSA, Malaysia. ${ }^{4}$ Department of Pharmacology, Manipal University, Manipal, Karnataka, India. ${ }^{5}$ Department of Dentistry, MCODS, Manipal, Karnataka, India. ${ }^{6}$ Department of Pedodontics and Preventive Dentistry, Manipal University, Manipal, Karnataka, India. Email: praveenkarnati@segi.edu.my

Received: 05 February 2017, Revised and Accepted: 13 April 2017

ABSTRACT

Objective: To measure and compare the amount, rate and anchor loss after the en masse retraction of all anteriors with titanium mini-implant anchorage and conventional molar anchorage.

Methods: This comparative clinical study sample comprised 12 patients (10 females, 2 males; mean age between 16 and 22 years). The implants were placed in the maxillary and mandibular arches. Preretraction and post retraction lateral cephalograms were taken for measuring the amount, rate and anchor loss after the retraction.

Results: Mean en masse retraction amounts, the rate of movement per month, and horizontal and vertical anchor loss at the maxillary implant site were $4.79 \mathrm{~mm}, 0.58 \mathrm{~mm}, 0 \mathrm{~mm}$, and $0 \mathrm{~mm}$, respectively. In the mandible, on implant sides were $4.66 \mathrm{~mm}, 0.56 \mathrm{~mm}, 0 \mathrm{~mm}$, and $0 \mathrm{~mm}$. Mean en masse retraction amounts, the rate of movement per month, and horizontal and vertical anchor loss at the maxillary conventional molar anchor side were $4.08 \mathrm{~mm}, 0.49 \mathrm{~mm}, 2.91 \mathrm{~mm}$, and $1.66 \mathrm{~mm}$. In the mandible, on conventional anchor sides were $3.54 \mathrm{~mm}, 0.48 \mathrm{~mm}, 3.12 \mathrm{~mm}$, and $1.95 \mathrm{~mm}$.

Conclusion: En masse retraction had a faster rate of space closure with mini-implants as anchor units than the conventional molar anchorage preparation.

Keywords: Anchorage redefined, Bimaxillary protrusion, Segmental retraction, Temporary anchorage devices.

(C) 2017 The Authors. Published by Innovare Academic Sciences Pvt Ltd. This is an open access article under the CC BY license (http://creativecommons. org/licenses/by/4. 0/) DOI: http://dx.doi.org/10.22159/ajpcr.2017.v10i7.17504

\section{INTRODUCTION}

Bialveolar dental protrusion is a common clinical picture in many ethnic groups around the world with dentoalveolar protrusion of both maxillary and the mandibular anterior teeth with concomitant protrusion of the lips and convexity of the face [1-4]. Various anchorage techniques have been designed for simultaneous retraction of all anterior teeth in bialveolar dental protrusion patients undergoing the extractions of four first premolars, such as banding of the second molars, trans-palatal arches, and headgear sand application of differential movements with the emphasis of Burstone on how the anchorage is managed $[5,6]$.

The use of skeletal anchorage to apply force directly to dental arches would be more desirable and can be placed in various locations within the bone. However, with the exception of osseointegrated titanium implants, non-osseointegrated implants have not been shown to remain stable on a long-term basis [7-10].

This trend to treat bialveolar protrusion being extraction of the four first premolars, followed by anterior tooth retraction to obtain the desired skeletal, dental and soft tissue profile changes [11-14], this study was conducted to compare the amount, rate and anchor loss during retraction of the anterior teeth using split-mouth technique.

\section{METHODS}

This study was conducted on 12 patients (10 females and 2 males) who presented with bialveolar dental protrusion, to the Department of Orthodontics, Narayana Dental College, Nellore, which was reviewed and approved by the Institutional Ethical Committee.

The subjects underwent extractions of all first premolars. Full mouth labial bonding was done in one appointment using stainless steel brackets (3M Unitek, Gemini: MBT-0.022 prescription) according to the diagnosis and treatment planning. To differentiate right and left sides in the lateral cephalogram, the jig is modified as on the patient right side it is placed distally, and on the patient left side, it is placed mesially. Tracing was done for right and left canines by taking vertical tie-wings of the canine brackets into consideration. Positioner: A sectional implant positioner was prepared manually by $0.016 \times 0.022$ stainless steel wire and was placed in the main slot of molar buccal tubes in both upper and lower arches on the selected side (Fig. 1).

Tomas titanium mini-implants of $1.6 \mathrm{~mm}$ in diameter, $8 \mathrm{~mm}$ in length (temporary orthodontic micro anchorage system - pin designed by Dr. Bumann, Dentaurum, Germany) were used on the right side of the patient in both upper and lower arches These Pins were positioned at the maximum thickness of interdental bone between the roots of the 
first molar and second premolar on the same quadrants in the maxillary and mandibular arches.

A $0.017 \times 0.025$-inch stainless steel true form arch wires (Rabbit Force, USA), crimped and soldered with the hooks. A 7-mm lever arm hook between lateral incisor and canine on mini-implant anchorage side and without lever arm between lateral incisor and canine on conventional molar anchorage side, placed in both upper and lower arches. Load application: Nickel titanium close coil springs with a force of $150 \mathrm{~g}$ stretched on both sides. The implants were immediately loaded with pre-calibrated nickel titanium closed coil springs extending from the implant head to the archwire hook for the anterior retraction of the maxillary and mandibular teeth with $150 \mathrm{~g}$ force on all the sides. Direction of the applied force was backward for the maxillary arch and the mandibular arch (Fig. 2).

Two sets of photographs and lateral cephalometric radiographs were taken, one before retraction $\mathrm{T} 1$ and the other after retraction $\mathrm{T} 2$, to calculate the amount of extraction space utilized by the retraction of anterior teeth. Posterior vertical line was drawn from the pterygoid vertical passing perpendicular to the $\mathrm{X}$-axis and parallel to the Y-axis, anterior vertical line was drawn from the perpendicular line passing from the X-axis, which touches the distal tip of the retraction hooks on both sides separately, between these two lines individual horizontal line parallel to X-axis drawn to measure the distance and calculate the amount of anterior retraction (Fig. 3). Legan and Burstone correction with $7^{\circ}$ from the sella-nasion plane was considered the X-axis (constructed horizontal, which tends to be parallel to true horizontal) and the line perpendicular to it through the sella considered the Y-axis [15]. The lateral cephalograms were traced by three orthodontists twice to alleviate the inter- and intraobserver errors. The data were documented and verified for gross variations.

The rate of retraction is calculated by dividing the amount of space that is closed to the time taken for the complete en masse retraction of the anterior teeth, which was considered to be the per month movement of the anterior teeth. The changes in the sagittal positioning of the first permanent molars in the maxillary and mandibular arches were measured by taking Y-axis as a reference plane. The changes in the vertical positioning of the first permanent molars in the maxillary and mandibular arches were measured by taking X-axis as the reference plane.

\section{Statistical analysis}

Data analysis was performed using the Statistical Package for Social Sciences (SPSS version 16). Individual Student's test was used to determine the significant difference in relation to the amount of en masse retraction, the rate of en masse retraction and comparison of anchor loss of en masse retraction between sides in the maxilla and mandible. Mean and standard deviation was used to represent the tabulated data. The level of significance was set at $\mathrm{p}<0.05$ for the abovementioned one.

\section{RESULTS}

The changes for each measurement were calculated by subtracting the pre-treatment from the post-treatment measurements. En masse retraction was considered complete when the extraction space was closed on the implant anchor side. The duration of the study was for 9-12 months. Horizontal and vertical anchor loss was measured in millimeters after completion of the retraction.

The mean and standard deviation of distal movement of all anterior teeth with implants as anchorage were $4.79 \mathrm{~mm}, 0.23(\mathrm{p} \leq 0.05)$ in the maxilla and $4.67 \mathrm{~mm}, 0.22(\mathrm{p} \leq 0.05)$ in the mandible. The distal movements of all anterior teeth with conventional molar anchorage were $3.69 \mathrm{~mm}, 0.17(\mathrm{p} \leq 0.05)$ in the maxilla and $3.67 \mathrm{~mm}, 0.12$ in the mandible (Table 1). The average differences between the implant and conventional anchor sides were $1.1 \mathrm{~mm}, 0.06$ in the maxilla and $1.00 \mathrm{~mm}, 0.10$ in the mandible.

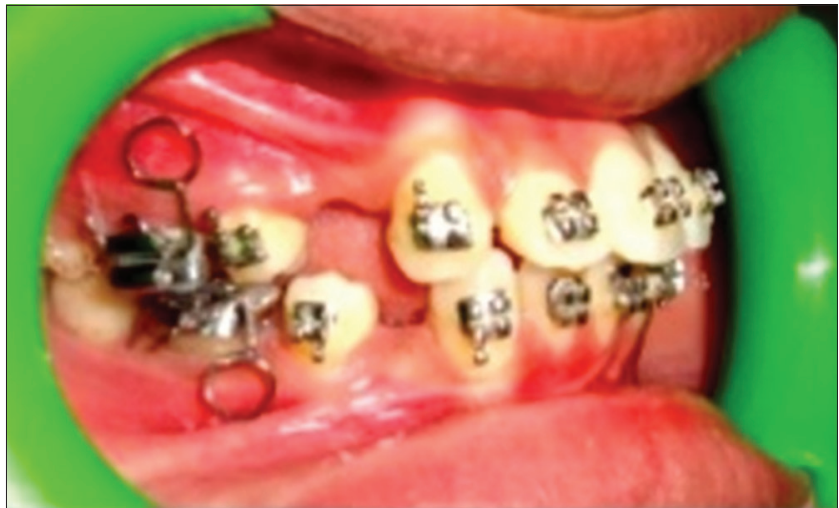

Fig. 1: A sectional implant positioner

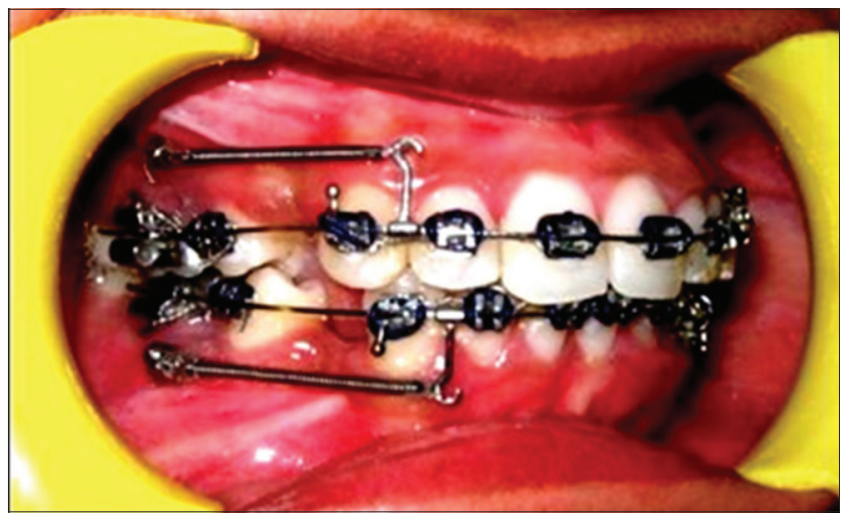

Fig. 2: Implants load with nickel titanium closed coiled springs

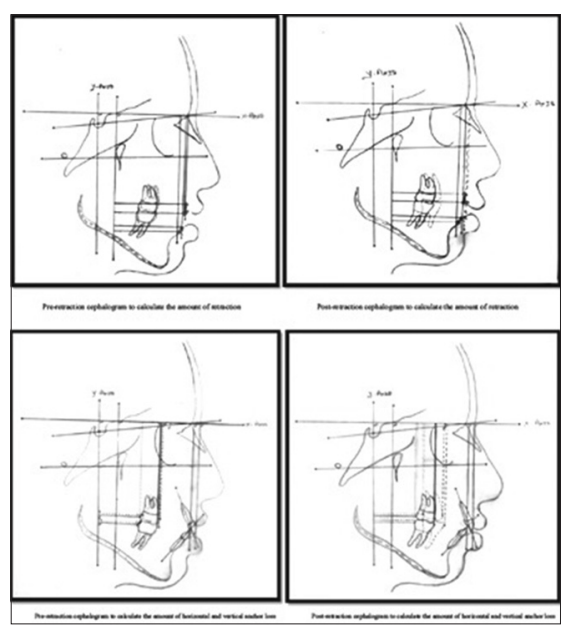

Fig. 3: Pre-and post-cephalometric tracings

The mean and standard deviation rates of en masse retraction were $0.58 \mathrm{~mm}, 0.006(\mathrm{p} \leq 0.05)$ per month in the maxilla and $0.57 \mathrm{~mm}, 0.005$ $(\mathrm{p} \leq 0.05)$ per month in the mandible on the implant-anchored side, and $0.45 \mathrm{~mm}, 0.003(\mathrm{p} \leq 0.05)$ per month in the maxilla and $0.43 \mathrm{~mm}$, $0.004(\mathrm{p} \leq 0.05)$ per month in the mandible on the molar-anchored side Table 1 . The mean differences in the rate of en masse retraction were $0.13 \mathrm{~mm}, 0.003$ per month in the maxilla and $0.14 \mathrm{~mm}, 0.001$ per month in the mandible.

The mean and standard deviation of horizontal anchor loss after completion of the retraction were $0 \mathrm{~mm}$ in the maxilla and mandible on the implant anchor side, and $2.91 \mathrm{~mm}, 0.28(\mathrm{p} \leq 0.01)$ in the maxilla and $3.12 \mathrm{~mm}, 0.22(\mathrm{p} \leq 0.01)$ in the mandible on the molar anchor side (Table 2). 
The mean and standard deviation of vertical anchor loss after completion of the retraction were $0 \mathrm{~mm}$ in the maxilla and mandible on the implant anchor side, and $1.67 \mathrm{~mm}, 0.82(\mathrm{p} \leq 0.01)$ in the maxilla and $1.96 \mathrm{~mm}, 0.38(\mathrm{p} \leq 0.01)$ in the mandible on the molar anchor side (Table 2).

\section{DISCUSSION}

With temporary implant anchorage, forces can be applied to produce tooth movement in any direction without detrimental reciprocal forces [16]. The stability and resistance to failure of bone screws used for rigid fixation are known to depend on many variables including implant material diameter, length, thread design, surgical placement protocol, and the recipient bone qualities [17-22]. Patient sex showed no significant differences on the rate of tooth movement [23]. Screws with $1.2 \mathrm{~mm}$ diameter with $8 \mathrm{~mm}$ length were preferred because they were stable and minimized the risk of root damage, the success rate was $90 \%$. It showed significantly higher success rates for maxillary than for mandibular screws.

The first such study for comparing this relationship was by Story and Smith who reported an optimum force of 150-200 g for retraction of the mandibular canines. Lee recommended 150-200 g as the optimum pressure value for canine retraction. Boester and Johnston reported 140-300 g. Huffman and Way advocated $200 \mathrm{~g}$ as the optimum force. Crismani et al. reported that higher forces produce more effective tooth movement [23].

Badri Thiruvenkatachari reported the mean amount of canine retraction as $4.29 \mathrm{~mm}$ in the maxilla and $4.10 \mathrm{~mm}$ in the mandible on the implant anchorage side, compared to $3.79 \mathrm{~mm}$ in the maxilla and $3.75 \mathrm{~mm}$ in the mandible on the molar anchorage side [24]. In this study, all anterior teeth were successfully retracted in all subjects. The amounts of distal movement of all anterior teeth with implants as anchorage were $4.79 \mathrm{~mm}$ in the maxilla and $4.67 \mathrm{~mm}$ in the mandible. The distal movements of the all anterior teeth with conventional molar anchorage were $3.69 \mathrm{~mm}$ in the maxilla and $3.67 \mathrm{~mm}$ in the mandible. The average differences between implant and conventional anchor sides were $1.1 \mathrm{~mm}$ in the maxilla and $1.00 \mathrm{~mm}$ in the mandible. These values were statistically significant. Paulsen et al. showed an average canine retraction rate of 1 mmper month [25].

In the study of Sonis etal., the rates of canine retraction were $0.99-1.51 \mathrm{~mm}$ in 3 weeks [26]. In the study by Badri Thiruvenkatacharithe rates of canine retraction were $0.93 \mathrm{mmper}$ month in the maxilla and $0.83 \mathrm{~mm}$ per month in the mandible on the implant-anchored side, and $0.81 \mathrm{~mm}$ per month in the maxilla and $0.76 \mathrm{~mm}$ per month in the mandible on the molar-anchored side [24]. The mean differences in the rate of canine retraction were $0.12 \mathrm{~mm}$ per month in the maxilla and $0.07 \mathrm{~mm}$ per month in the mandible. In this study, the rate of en masse retraction was slower than the rate of individual canine retraction, but the difference between implant and conventional sides was very much similar to the Badri Thiruvenkatachari study of individual canine retraction.

In a randomized clinical trial by Dixon et al., the mean rate of canine retraction with nickel titanium coil springs was 0.81 mmper month [27]. Boester and Johnston showed canine retraction rates of 3.24 and $2.05 \mathrm{~mm}$ in 2 months in the maxilla and the mandible, respectively [28]. Their results were higher than in our study and can be attributed to the difference in force levels used. The results proved that implants were efficient anchors and produced faster en masse retraction.

The horizontal anchor loss in this study after completion of the retraction was $0 \mathrm{~mm}$ in the maxilla and mandible on the implant anchor side, and $2.91 \mathrm{~mm}$ in the maxilla and $3.12 \mathrm{~mm}$ in the mandible on the molar anchor side. The vertical anchor loss after completion of the retraction was $0 \mathrm{~mm}$ in the maxilla and mandible on the implant anchor side, and $1.67 \mathrm{~mm}$ in the maxilla and $1.96 \mathrm{~mm}$ in the mandible on the molar anchor side. At the end of the study, the asymmetric molar anchorage loss was managed by allowing mesial movement of the molars on the implant-anchored side.

Implants produced effective en masse retraction using the entire extraction space. With increasing demands on orthodontists to treat more patients in shorter times, attention to the quality of treatment is essential. Titanium micro implants can bring about more effective en masse retraction in a shorter time.

The success rate of the mini-implants was $93 \%$. Of the 24 implants placed, only two became loose with respect to mandibular arch, which was reloaded again after 10 days. The amount of en-masse retraction at the implant side was comparatively greater than the conventional side. The time taken for retraction was less for patients treated with mini-implants; the results were statistically and clinically significant. The molars were mesialized and intruded on the conventional side; as there were significant levels of anchorage loss in both horizontal and vertical directions.

Table 1: Comparison of amounts and rate of en masse retraction between sides in the maxilla and the mandible

\begin{tabular}{|c|c|c|c|}
\hline \multirow[t]{2}{*}{ En masse retraction } & \multicolumn{2}{|l|}{ Mean $\pm S D(m m)$} & \multirow[t]{2}{*}{$\mathbf{p}$} \\
\hline & Implant-anchored side & Molar anchor side & \\
\hline Amount of en masse retraction & & Mean \pm SD $(\mathrm{mm})$ & \\
\hline En masse retraction. Maxilla (n-12) & $4.79 \pm 0.23$ & $3.69 \pm 0.17$ & $*$ \\
\hline En masse retraction. Mandible (n-12) & $4.67 \pm 0.22$ & $3.67 \pm 0.12$ & $*$ \\
\hline \multicolumn{4}{|l|}{ Rate of en masse retraction } \\
\hline En masse retraction. maxilla (n-12) & $0.58 \pm 0.006$ & $0.45 \pm 0.003$ & $*$ \\
\hline
\end{tabular}

Table 2: Comparison of horizontal and vertical anchor loss of en-masse retraction between sides in the maxilla and the mandible

\begin{tabular}{llll}
\hline Anchor loss & Mean \pm SD $(\mathbf{m m})$ & & Significant \\
\cline { 2 - 4 } & Implant-anchored side & Molar-anchored side & p \\
\hline Horizontal anchor loss & & & $*$ \\
$\quad$ En masse retraction. maxilla (n-12) & $0 \pm 0$ & $2.91 \pm 0.28$ & $*$ \\
$\quad$ En masse retraction. mandible (n-12) & $0 \pm 0$ & $3.12 \pm 0.22$ & $*$ \\
Vertical anchor loss & $0 \pm 0$ & $1.67 \pm 0.82$ & $*$ \\
$\quad$ En masse retraction. maxilla (n-12) & $0 \pm 0$ & $1.96 \pm 0.38$ & \\
En masse retraction, mandible (n-12) & & \\
\hline
\end{tabular}




\section{CONCLUSION}

Implant anchorage contributes for faster and more en masse retraction than conventional molar anchorage. The use of implants as an anchorage for the en masse retraction is a viable alternative to conventional molar anchorage. As the findings of this study were based on lateral cephalogram which was a two-dimensional view of the threedimensional (3D) picture, so it is best advised to do the study with the latest $3 \mathrm{D}$ view techniques for more accurate findings and better evaluation.

\section{Critical appraisal}

The existing studies were mostly conducted on individual canine retraction comparing the rates of tooth movement with temporary anchorage devices, conventional retraction methods, and a combination. This study is peculiar in its methodology with en masse retraction of anterior teeth by split-mouth design for implant and conventional methods of retraction, for which more studies, are required to justify the results.

\section{REFERENCES}

1. Farrow AL, Zarrinnia K, Azizi K. Bimaxillary protrusion in black Americans - An esthetic evaluation and the treatment considerations. Am J Orthod Dentofacial Orthop 1993;104(2):240-50.

2. Dandajena TC, Nanda RS. Bialveolar protrusion in a Zimbabwean sample. Am J Orthod Dentofacial Orthop 2003;123(2):133-7.

3. Carter NE, Slattery DA. Bimaxillary proclination in patients of AfroCaribbean origin. Br J Orthod 1988;15(3):175-84

4. Angle EH. Classification of malocclusion. Dent Cosmos 1899;41(3):248-64.

5. Profitt WR. Text Book of Contemporary Orthodontics, Reprint. $4^{\text {th }}$ ed.. St. Louis, MO: Mosby, Elsevier; 2007. p. 343.

6. Cranin AN, Rabkin MF, Garfinkel L. A statistical evaluation of 952 endosteal implants in humans. J Am Dent Assoc 1977;94(2):315-20.

7. Burstone CJ. The segmented arch approach to space closure. Am J Orthod 1982;82(5):361-78

8. Guyman GW, Kokich VG, Oswald RJ. Ankylosed teeth as abutments for palatal expansion in the rhesus monkey. Am J Orthod 1980;77(5):486-99.

9. Gray JB, Steen ME, King GJ, Clark AE. Studies on the efficacy of implants as orthodontic anchorage. Am J Orthod 1983;83(4):311-7.

10. Roberts WE, Smith RK, Zilberman Y, Mozsary PG, Smith RS. Osseous adaptation to continuous loading of rigid endosseous implants. Am J Orthod 1984;86(2):95-111.

11. Bernstein L. Edward H. Angle versus Calvin S. Case: Extraction versus nonextraction. Part I. Historical revisionism. Am J Orthod Dentofacial Orthop 1992;102(5):464-70.
12. Drobocky OB, Smith RJ. Changes in facial profile during orthodontic treatment with extraction of four first premolars. Am J Orthod Dentofacial Orthop 1989;95(3):220-30.

13. Kusnoto J, Kusnoto H. The effect of anterior tooth retraction on lip position of orthodontically treated adult Indonesians. Am J Orthod Dentofacial Orthop 2001;120(3):304-7.

14. Talass MF, Talass L, Baker RC. Soft-tissue profile changes resulting from retraction of maxillary incisors. Am J Orthod Dentofacial Orthop 1987;91(5):385-94.

15. Gruner W, Karlsruhe K, Neulingen TL. Tomas ${ }^{\circledR}$ Insertion Manual. FDA Approved. Ispringen: Dentaurum; 2008.

16. Legan HL, Burstone CJ. Soft tissue cephalometric analysis for orthognathic surgery. J Oral Surg 1980;38(10):744-51.

17. Creekmore TD, Eklund MK. The possibility of skeletal anchorage. J Clin Orthod 1983;17(4):266-9.

18. Cheung LK, Zhang Q, Wong MC, Wong LL. Stability consideration for internal maxillary distractors. J Craniomaxillofac Surg 2003;31(3):142-8

19. Tengvall P, Skoglund B, Askendal A, Aspenberg P. Surface immobilized bisphosphonate improves stainless-steel screw fixation in rats. Biomaterials 2004;25(11):2133-8.

20. Gosain AK, Song L, Corrao MA, Pintar FA. Biomechanical evaluation of titanium, biodegradable plate and screw, and cyanoacrylate glue fixation systems in craniofacial surgery. Plast Reconstr Surg 1998;101(3):582-91.

21. You ZH, Bell WH, Schneiderman ED, Ashman RB. Biomechanical properties of small bone screws. J Oral Maxillofac Surg 1994;52(12):1293-302.

22. Gantous A, Phillips JH. The effects of varying pilot hole size on the holding power of miniscrews and microscrews. Plast Reconstr Surg 1995;95(7):1165-9.

23. Crismani AG, Bertl MH, Celar AG, Bantleon HP, Burstone CJ. Miniscrews in orthodontic treatment: Review and analysis of published clinical trials. Am J Orthod Dentofacial Orthop 2010;137(1):108-13.

24. Thiruvenkatachari B, Ammayappan P, Kandaswamy R. Comparison of rate of canine retraction with conventional molar anchorage and titanium implant anchorage. Am J Orthod Dentofacial Orthop 2008;134(1):30-5.

25. Paulson RC, Speidel TM, Isaacson RJ. A laminagraphic study of cuspid retraction versus molar anchorage loss. Angle Orthod 1970;40(1):20-7.

26. Sonis AL, Van der Plas E, Gianelly A. A comparison of elastomeric auxiliaries versus elastic thread on premolar extraction site closure: An in vivo study. Am J Orthod 1986;89(1):73-8.

27. Dixon V, Read MJ, O'Brien KD, Worthington HV, Mandall NA. A randomized clinical trial to compare three methods of orthodontic space closure. J Orthod 2002;29(1):31-6.

28. Boester $\mathrm{CH}$, Johnston LE. A clinical investigation of the concepts of differential and optimal force in canine retraction. Angle Orthod 1974;44(2):113-9. 